\section{Impacto do Código de Trânsito Brasileiro e da Lei Seca na mortalidade por acidentes de trânsito}

\author{
Impact of the Brazilian Traffic Code and the Law \\ Against Drinking and Driving on mortality from \\ motor vehicle accidents
}
Impacto del Código de Tráfico Brasileño y la Ley Seca en la mortalidad por accidentes de tráfico

Débora Regina de Oliveira Moura Abreu 1

Eniuce Menezes de Souza 1

Thais Aidar de Freitas Mathias 1

\title{
Resumo
}

O objetivo foi analisar o impacto do Código de Trânsito Brasileiro (CTB) e da Lei Seca na mortalidade por acidentes de trânsito no Estado do Paraná, Brasil, no período de 1980 a 2014. Estudo ecológico de séries temporais das taxas de mortalidade por acidentes de trânsito de residentes de 15 a 49 anos por sexo, idade e categorias das vítimas, com dados do Sistema de Informações sobre Mortalidade. O estudo da tendência foi realizado por meio do modelo de regressão linear segmentada e pelo procedimento iterativo de Cochrane-Orcutt. O pressuposto de independência dos resíduos foi verificado por correlogramas e teste de Box-Pierce. Em todo o período, as maiores taxas de mortalidade foram observadas para sexo masculino, motociclistas e faixa etária de 20 a 29 anos de idade. Após a implantação do CTB, houve redução de 9,69 óbitos, por ano, para todas as categorias de acidentes de trânsito $(p<0,001)$, de 6,90 para pedestres $(p=0,001)$ e de 1,96 para ocupantes de veículo $(p<0,001)$. Quanto à faixa de etária, o maior impacto na mortalidade foi observado de 15 a 19 anos para pedestres $(p<0,001)$ e entre 20 a 29 anos para todas as categorias ( $p<$ 0,001). Após a Lei Seca, os dados apresentaram variabilidade e as tendências não foram significativas. Entretanto, houve diminuição da mortalidade para a categoria geral e pedestre. Para as categorias de motociclista e veículo, houve estabilização das taxas. Os resultados mostram impacto nas taxas de mortalidade por acidentes de trânsito após a implantação do CTB e da Lei Seca, com posterior aumento destas. Evidencia-se a demanda por efetividade na fiscalização das leis e avanço nas políticas públicas para que não haja retrocesso no já realizado.

Acidentes de Trânsito; Avaliação em Saúde; Mortalidade; Estudos de Séries Temporais

\author{
Correspondence \\ D. R. O. M. Abreu \\ Departamento de Enfermagem, Universidade Estadual de \\ Maringá. \\ Av. Colombo, Jardim Universitário, Maringá, PR 87020-900, \\ Brasil. \\ debora.drom@gmail.com \\ 1 Departamento de Enfermagem, Universidade Estadual de \\ Maringá, Maringá, Brasil.
}




\section{Introdução}

Os acidentes de trânsito representam grave problema de saúde pública global. Diariamente, milhares de pessoas perdem suas vidas ou são feridas no trânsito tanto nas rodovias como nas zonas urbanas. Em 2012, foram registradas 1,3 milhão mortes por acidentes de trânsito no mundo e esses índices são mais elevados em países de renda baixa e média, onde se concentram mais de $80 \%$ dessas mortes, mesmo com a metade da frota de veículos se comparada àquela dos países de alta renda per capita 1. Estima-se que, caso nenhuma atitude seja tomada para reverter tal cenário, em 2020 as mortes no trânsito poderão atingir 1,9 milhão pessoas no mundo e podem vir a se tornar a $5 \underline{a}$ maior causa de mortalidade em 20301.

Mundialmente, $77 \%$ das mortes por acidentes de trânsito vitimam a população masculina jovem. Entre os homens de 15 a 29 anos de idade, os acidentes representam a principal causa de morte, e entre os de 30 a 49 anos, a 3a causa ${ }^{1}$. Em relação à categoria da vítima, os ocupantes de veículos a motor, seguidos dos pedestres e motociclistas são, respectivamente, aqueles com maior risco, responsáveis por $36 \%, 35 \%$ e $16 \%$ de todas as mortes no trânsito 2 .

O Brasil é um dos países com maior número de mortes no trânsito, precedido apenas por Índia, China, Estados Unidos e Rússia 1. De 1980 a 2011, quase um milhão de pessoas morreram por acidentes de trânsito no país; de 2000 a 2010, o número de óbitos subiu de 28.995 para 42.844, aumento de $32,3 \%$ na década 3 . A taxa de mortalidade por acidente de trânsito no país em 2011 foi de 22,5 óbitos por 100 mil habitantes, sendo o sexo masculino responsável por $82,3 \%$ desse total 3 . Em relação às regiões do país, as taxas mais elevadas ocorreram nas regiões Centro-oeste e Sul, com valores de 29,0 e 25,4 óbitos por 100 mil habitantes, respectivamente 4.

Se por um lado as taxas de mortalidade por acidentes de trânsito são elevadas no Brasil e com tendência de aumento, existem evidências de que uma legislação mais rigorosa e punições mais severas aos infratores são determinantes na redução do número de acidentes de trânsito e da mortalidade, pois esses agravos são evitáveis e previsíveis 5 . Repetidas intervenções legislativas e punições severas aos infratores têm impactado nos acidentes de trânsito no Japão 6 . No Irã e na Inglaterra, também foi possível reduzir o número de mortes por meio do controle da velocidade, controle do consumo de álcool, a promoção da utilização do cinto de segurança e do capacete 7,8 .

No Brasil, algumas formas de enfrentamento e controle de acidentes no trânsito foram implementadas, entre elas se destacam o Código de Trânsito Brasileiro (CTB), em 1998, que define atribuições aos órgãos ligados ao trânsito e estabelece normas de conduta, infrações e penalidades para os usuários 9. Outra medida implementada pelo setor público, a Lei Seca, de 2008, alterou parte do CTB e instituiu taxa de alcoolemia zero para todos os condutores de veículo automotor e estabeleceu penalidades como multa, suspensão do direito de dirigir por 12 meses e apreensão do veículo na identificação de qualquer concentração de álcool por litro de sangue e mais, classificou como crime com pena de reclusão, quando a concentração de álcool for superior a 0,6g/L 10 .

Estudos brasileiros analisaram o impacto dessas legislações nos acidentes de trânsito e mostraram que o efeito do CTB começou a ser sentido, em todo o país, já durante o Carnaval de 1998, um mês após o início de sua vigência, quando houve uma redução de $45 \%$ no número de acidentes em relação ao mesmo período de 1997 11. Em relação à Lei Seca, pesquisa realizada nas capitais brasileiras identificou que nos dois primeiros meses após a sua implantação no país, em 2008, a frequência dos condutores que informaram dirigir após beber diminuiu de 2,2\% para 1,3\%, mas voltou a aumentar para 2,8\%, em 2009 12. Outros estudos estimam que a Lei Seca foi responsável pela redução em 28,3\% das internações hospitalares decorrentes de acidentes de trânsito, em $42 \%$ do tempo de internação e em $36 \%$ dos gastos hospitalares, que por sua vez resultou em economia de mais de R $\$ 23$ milhões aos cofres públicos 13 .

No Estado do Paraná, para atingir a meta de redução de óbitos por acidentes de trânsito, a Secretaria de Estado de Saúde aderiu ao Projeto Vida no Trânsito (PVT) 14 em 2010, uma parceria que envolve instituições nacionais, internacionais e locais, com o objetivo de subsidiar gestores no fortalecimento de políticas de prevenção de lesões e mortes no trânsito por meio da qualificação, planejamento, monitoramento, acompanhamento e avaliação das ações. Uma das atividades do PVT é intervir nos fatores de risco para acidentes de trânsito, entre eles: dirigir após o consumo de bebida alcoólica e velocidade excessiva e/ou inadequada. 
Embora estudos tenham evidenciado queda nos acidentes após implantação de políticas e legislações de trânsito, tais agravos persistem, resultando em taxas de mortalidade ainda muito elevadas no Brasil se comparadas às de outros países. Por isso são necessárias pesquisas que abordem o impacto das duas principais políticas públicas nacionais nos óbitos por acidentes trânsito para as principais categorias de vítimas: ocupantes de veículos a motor, pedestres e motociclistas. Esses resultados podem contribuir para a avaliação e a adequação dessas políticas e para a formulação de programas de promoção da saúde e prevenção dos acidentes de trânsito. Este estudo teve como objetivo analisar o impacto do CTB e da Lei Seca na mortalidade por acidentes de trânsito no Estado do Paraná na série histórica de 1980 a 2014.

\section{Métodos}

Estudo ecológico da mortalidade por acidentes de trânsito de residentes de 15 a 49 anos no Estado do Paraná no período de 1980 a 2014. A seleção da faixa etária atendeu ao propósito de representar uma população em idade produtiva e com alto risco de morte pelas causas estudadas 1. Estratificou-se em: 15 a 19 anos; 20 a 29 anos; 30 a 39 anos e 40 a 49 anos.

Utilizaram-se dados do Sistema de Informações sobre Mortalidade do Sistema Único de Saúde (SIM-SUS). Foram analisados os óbitos por acidentes de trânsito codificados nas categorias E810 a E819 da 9a revisão da Classificação Internacional de Doenças (CID-9) 15 para os anos de 1980 a 1995, e V01 a V89 conforme a CID-10 16 para os anos de 1996 a 2014, os óbitos foram agrupados segundo as categorias de acidentes de trânsito: geral (todas as categorias de acidentes de trânsito), veículo, motociclista e pedestres. Para assegurar a correspondência entre as revisões da CID, foi estabelecida a equivalência entre as 9a e 10a revisões. As informações referentes à população residente foram coletadas no Departamento de Informática do Sistema Único de Saúde (DATASUS. http://www2.datasus. gov.br/DATASUS/index.php, acessado em 16/Jul/2017).

A análise da mortalidade por acidentes de trânsito no Estado do Paraná foi feita por meio de um modelo de regressão linear segmentado para séries temporais que estimou a tendência das taxas em função do tempo 17,18, de modo que a implantação do CTB em 1998 e da Lei Seca em 2008 fossem considerados no modelo como intervenções, o que permitiu a análise do impacto dessas políticas públicas, uma novidade no estudo de análise de tendência.

Para a obtenção do modelo ${ }^{19}$, foram investigadas as mudanças na tendência das taxas de mortalidade tanto abruptas quanto graduais. Para estimar a ocorrência de possíveis efeitos abruptos, inseriuse um parâmetro no modelo estatístico para detectar a mudança na taxa média no ano imediatamente posterior ao de implantação da intervenção. Já as mudanças graduais, temporárias ou permanentes, nas taxas de mortalidade, foram analisadas estimando as tendências se suas alterações em período subsequente à implantação da intervenção, em relação ao período anterior por meio da equação:

$$
Y_{t}=\beta_{0}+\beta_{1} t(1980-1997)+\beta_{2} I(1998-2014)+\beta_{3} t(1998-2007)+\beta_{4} t(2008-2014)+\varepsilon_{t}
$$

Onde:

$\mathrm{I}(\mathrm{x})$ : função indicadora do período $\mathrm{x}$;

$t(\mathrm{x})$ : indica uma sequência de anos do período $\mathrm{x}$;

$Y_{t}$ : é a taxa de mortalidade por ano (t) segundo faixa etária, sexo e categoria da vítima;

$\beta_{0}$ : é a taxa de mortalidade ajustada no início da série, em 1980;

$\beta_{1}$ : é a tendência linear no período de 1980 a 1997 anterior à implantação do CTB;

$\beta_{2}$ : estima a diferença na taxa média de mortalidade a partir do ano da implantação do CTB (de 1998 a 2014) em relação ao período anterior;

$\beta_{3}$ : estima a diferença na inclinação ou na tendência da taxa de mortalidade por acidente de trânsito no período de 1998 a 2007 comparada à tendência no período anterior (de 1980 a 1997);

$\beta_{4}$ : estima a alteração na tendência das taxas de mortalidade quando passa a vigorar a Lei Seca, último período da série (de 2008 a 2014);

$\varepsilon_{t}$ : representa a variabilidade aleatória não explicada pelo modelo e deve ser normalmente distribuída e não correlacionada. 
Em toda a série analisada, de 1980 a 2014, só houve mudança de tendência abrupta em 1998; logo, o modelo apresenta uma única estimativa de mudança abrupta em média dada por $\beta_{2} t_{1998}$. Para que as mudanças graduais causadas a partir da implantação do CTB e da Lei Seca pudessem ser estimadas, o modelo considerou a estimativa de tendência linear particionada em subperíodos de tempo: o primeiro de 1980 a 1997, o segundo de 1998 a 2007 e o terceiro de 2008 a 2014.

Para interpretar a tendência das taxas no período de 1998 a 2007 no modelo representado na Equação (1), avaliou-se a variação anual média, calculada por $\beta_{1}+\beta_{3}$, e, quando passa a vigorar a Lei Seca em 2008, a tendência resultante ou a variação anual média é representada por $\beta_{1}+\beta_{3}+\beta_{2}$.

Após estimação das tendências, o pressuposto de independência dos resíduos foi verificado a partir de correlogramas e do teste de Box-Pierce 20 , que avalia a autocorrelação temporal não modelada nos resíduos. Para as séries em que os erros estimados apresentaram autocorrelação significativa o procedimento iterativo de Cochrane-Orcutt foi aplicado para adequação do modelo 21. Com base na tendência estimada e seu respectivo erro padrão, foi possível verificar a existência ou alteração de tendência crescente ou decrescente estatisticamente significativa ( $\mathrm{p}<0,005)$.

Vale ressaltar que o modelo de regressão linear segmentado, representado na Equação (1), foi estimado separadamente para cada uma das séries temporais analisadas. De 1980 a 1992, pode ter havido subnotificação de dados de óbitos por acidentes de trânsito nas categorias veículos e motociclistas, mas sem tendência aparente. Nesse caso, foi realizada quebra estrutural no modelo para um melhor ajuste. Assim, a análise da tendência no período anterior à implantação do CTB (1980 a 1997) já inclui tal quebra, de modo que a interpretação é feita da mesma maneira que para as demais séries.

A implementação para gerar as séries temporais, estimar os modelos e realizar as análises foi feita em linguagem R, versão 3.2.3 (https://www.r-project.org/). Foi utilizada função lm do pacote "stats" para o ajuste dos modelos de regressão linear e as demais implementações tais como o algoritmo de Cochrane-Orcutt foram feitas pelos autores. O projeto de pesquisa foi aprovado pelo Comitê Permanente de Ética em Pesquisa Envolvendo Seres Humanos (COPEP), da Universidade Estadual de Maringá, parecer no 1.329.069/2008, de acordo com a Resolução no 466/2012 do Conselho Nacional de Pesquisa.

\section{Resultados}

A Figura 1 mostra as séries temporais das taxas de mortalidade (por 100 mil habitantes de 15 a 49 anos) por acidentes de trânsito, geral (todas as categorias de acidentes de trânsito), por veículo, motociclista e pedestre, por sexo e faixa etária. A análise visual das curvas, além do aumento das taxas de mortalidade segundo as categorias veículo e motociclistas, chama a atenção a mortalidade masculina em todas as situações analisadas. Em relação à idade, as curvas mostram que para os motociclistas, as pessoas de 20 a 29 têm maior ocorrência de mortalidade, em todo o período, e para os acidentes por veículo essa faixa de idade também apresenta maiores taxas a partir de 2000. Para os pedestres, houve aumento da mortalidade a partir de 1985, e em 1995 as taxas atingem os valores mais elevados, declinando no restante do período. As taxas de mortalidade para pedestres são mais elevadas para as pessoas de 40 a 49 anos de idade.

$\mathrm{Na}$ Tabela 1, são apresentadas as estimativas da variação na média e variação anual (tendência) bem como o valor p indicando a significância de tais estimativas em cada período. No período de 1980 a 1997, observou-se tendência ascendente para a categoria geral, com aumento de 0,62 óbitos por ano ou quase dois óbitos a cada três anos na taxa de mortalidade $(\mathrm{p}<0,001)$, e também para as categorias de motociclista com aumento de $0,12(\mathrm{p}=0,002)$ e pedestre $1,04(\mathrm{p}<0,001)$. Em 1998, ano da implantação do CTB, ocorreu redução de 9,69 óbitos por ano em 100 mil habitantes na taxa de mortalidade para a categoria geral $(\mathrm{p}<0,001)$, de 6,90 para pedestre $(\mathrm{p}=0,001)$ e, de 1,96 para veículo $(\mathrm{p}<0,001)$. Portanto, a maior redução da mortalidade em 1998 foi na categoria geral, com decréscimo na taxa média anual de aproximadamente dez óbitos em 100 mil habitantes. Na categoria de motociclistas, não se encontraram reduções significativas com a implantação do CTB.

Após 1998, a tendência ascendente da mortalidade é retomada para as categorias de motociclista e veículo além da faixa etária de 15 a 29 anos na categoria geral ( $\mathrm{c}<0,05)$. Analisando a Tabela 1 , tal tendência chegou a atingir um aumento de quase duas mortes ao ano em 100 mil habitantes para motociclistas do sexo masculino $(\mathrm{p}<0,001)$. 


\section{Figura 1}

Taxas de mortalidade por acidentes de trânsito, geral, veículo, motociclista e pedestres (por 100 mil habitantes) por idade e sexo. Paraná, Brasil, 1980 a 2014.
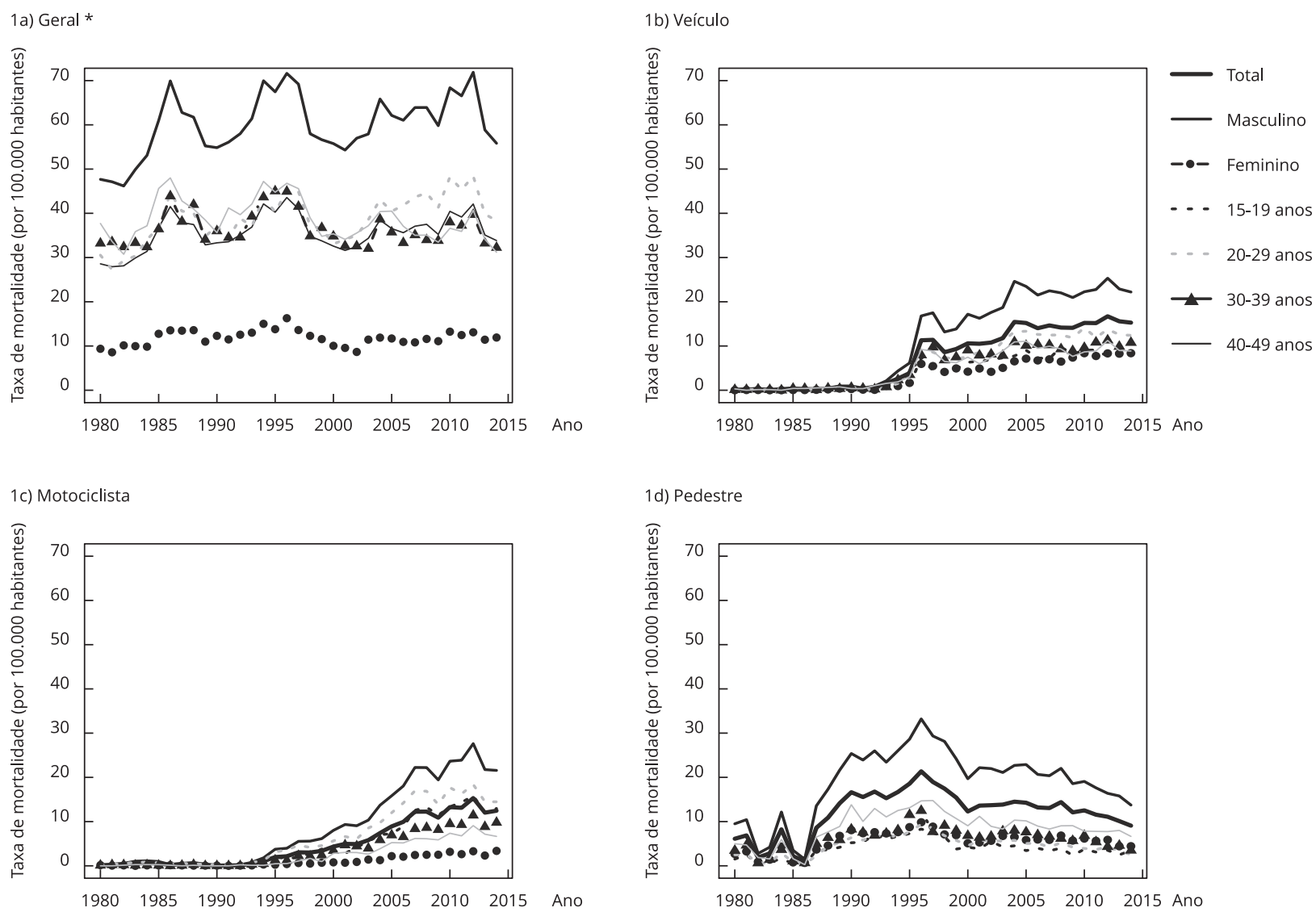

* Todas as categorias de acidentes de trânsito.

Para os pedestres, após a diminuição das taxas com a implantação do CTB em 1998, a tendência, que anteriormente era de aumento, ficou nula ( $\mathrm{p}>0,05)$, ou seja, não existiu tendência significativamente diferente de zero, implicando uma estabilização nas taxas de mortalidade no período de 1998 a 2007. Esse fato aconteceu para ambos os sexos e em todas as idades (Tabela 1).

Após a implantação da Lei Seca, houve declínio nas taxas de mortalidade para a categoria geral $(-0,26 ; p=0,742)$, indicando a diminuição média de um óbito a cada quatro anos em 100 mil habitantes. Para os pedestres, o declínio anual de 0,71 óbitos a cada 100 mil habitantes $(\mathrm{p}=0,270)$ representou uma diminuição média de dois óbitos a cada três anos. Porém, para ambas as categorias, o declínio não foi significativo (Tabela 1).

Para as categorias de motociclista e veículo, também não houve tendência significativa que indique uma estabilização de tais taxas ou aumento mais suave; sendo, por exemplo, de um óbito a cada cinco anos para motociclista $(0,19 ; \mathrm{p}=0,402)$. Em relação às taxas de mortalidade estimadas, destacam-se os motociclistas, para os quais a taxa variou de 3,55 óbitos em 1997 para 23,65 óbitos em 2014, e com projeção de 26,37 óbitos para o ano de 2025 para o sexo masculino (Tabela 1), caso a tendência estimada no último período da série permaneça inalterada.

Nas Figuras 2 e 3, são apresentadas as curvas dos modelos estimadas para a tendência das taxas de mortalidade para os acidentes de trânsito, por categoria da vítima, por sexo e faixa de idade. Em 1998, 
Tabela 1

Tendência da mortalidade por acidentes de trânsito antes e após a implantação do Código de Trânsito Brasileiro (CTB) 9 e da Lei Seca 10. Paraná, Brasil, 1980 a 2014.

\begin{tabular}{|c|c|c|c|c|c|c|c|}
\hline Categorias & $\begin{array}{c}\text { Tendência } \\
\text { 1980-1997 } \\
\text { (valor de p) }\end{array}$ & $\begin{array}{c}\text { СТВ } \\
\text { Mudança na } \\
\text { média } \\
\text { 1998-2014 } \\
\text { (valor de p) }\end{array}$ & $\begin{array}{c}\text { Pós CTB e antes } \\
\text { da Lei Seca } \\
\text { Tendência } \\
\text { 1998-2007 } \\
\text { (valor de p) }\end{array}$ & $\begin{array}{c}\text { Pós Lei Seca } \\
\text { Tendência } \\
\text { 2008-2014 } \\
\text { (valor de p) }\end{array}$ & $\begin{array}{c}\text { Taxa } \\
\text { ajustada } \\
\text { em } 1997\end{array}$ & $\begin{array}{c}\text { Taxa } \\
\text { ajustada } \\
\text { em } 2014\end{array}$ & $\begin{array}{c}\text { Projeção } \\
\text { da taxa } \\
\text { para } \\
2025\end{array}$ \\
\hline \multicolumn{8}{|l|}{ Geral * } \\
\hline \multicolumn{8}{|l|}{ Sexo } \\
\hline Masculino & $1,02(<0,001)$ & $-14,87(0,001)$ & $1,23(0,051)$ & $-0,72(0,596)$ & 68,21 & 61,32 & 54,14 \\
\hline Feminino & $0,27(<0,001)$ & $-4,69(<0,001)$ & $0,17(0,236)$ & $0,12(0,707)$ & 14,63 & 12,39 & 13,59 \\
\hline \multicolumn{8}{|c|}{ Faixa etária (anos) } \\
\hline $15-19$ & $0,63(<0,001)$ & $-9,75(<0,001)$ & $1,03(0,011)$ & $0,46(0,590)$ & 30,90 & 34,15 & 38,72 \\
\hline $20-29$ & $0,68(<0,001)$ & $-11,52(<0,001)$ & $1,36(0,002)$ & $-0,64(0,485)$ & 43,31 & 41,62 & 35,24 \\
\hline $30-39$ & $0,46(0,002)$ & $-7,60(0,007)$ & $0,13(0,746)$ & $-0,04(0,967)$ & 41,72 & 35,17 & 34,82 \\
\hline $40-49$ & $0,48(0,003)$ & $-9,52(0,002)$ & $0,17(0,684)$ & $-0,51(0,581)$ & 45,03 & 34,13 & 28,98 \\
\hline Total & $0,62(<0,001)$ & $-9,69(<0,001)$ & $0,70(0,059)$ & $-0,26(0,742)$ & 41,00 & 36,72 & 34,08 \\
\hline \multicolumn{8}{|l|}{ Motociclista } \\
\hline \multicolumn{8}{|l|}{ Sexo } \\
\hline Masculino & $0,23(0,002)$ & $-0,46(0,729)$ & $1,89(<0,001)$ & $0,27(0,526)$ & 3,55 & 23,65 & 26,37 \\
\hline Feminino & $0,02(0,043)$ & $-0,15(0,421)$ & $0,24(<0,001)$ & $0,09(0,164)$ & 0,35 & 3,09 & 3,95 \\
\hline \multicolumn{8}{|c|}{ Faixa etária (anos) } \\
\hline $15-19$ & $0,10(0,029)$ & $-1,26(0,143)$ & $1,18(<0,001)$ & $0,28(0,315)$ & 1,68 & 13,92 & 16,68 \\
\hline $20-29$ & $0,19(0,001)$ & $-0,91(0,366)$ & $1,47(<0,001)$ & $-0,22(0,500)$ & 2,90 & 15,40 & 13,23 \\
\hline $30-39$ & $0,09(0,003)$ & $0,59(0,266)$ & $0,67(<0,001)$ & $0,26(0,127)$ & 1,27 & 10,14 & 12,76 \\
\hline $40-49$ & $0,05(0,069)$ & $0,21(0,659)$ & $0,55(<0,001)$ & $0,20(0,180)$ & 0,70 & 7,62 & 9,66 \\
\hline Total & $0,12(0,002)$ & $-0,31(0,661)$ & $1,05(<0,001)$ & $0,19(0,402)$ & 1,93 & 13,32 & 15,23 \\
\hline \multicolumn{8}{|l|}{ Pedestre } \\
\hline \multicolumn{8}{|l|}{ Sexo } \\
\hline Masculino & $1,63(<0,001)$ & $-10,08(0,001)$ & $-0,15(0,732)$ & $-1,16(0,238)$ & 32,61 & 14,10 & 2,54 \\
\hline Feminino & $0,47(<0,001)$ & $-3,77(<0,001)$ & $0,06(0,691)$ & $-0,29(0,384)$ & 9,54 & 4,62 & 1,72 \\
\hline \multicolumn{8}{|c|}{ Faixa etária (anos) } \\
\hline $15-19$ & $0,44(<0,001)$ & $-3,59(<0,001)$ & $-0,10(0,395)$ & $-0,09(0,715)$ & 8,15 & 3,01 & 2,08 \\
\hline $20-29$ & $0,46(<0,001)$ & $-2,97(0,001)$ & $-0,09(0,485)$ & $-0,32(0,254)$ & 8,70 & 2,91 & $-0,33$ \\
\hline $30-39$ & $0,51(<0,001)$ & $-3,02(0,021)$ & $-0,06(0,726)$ & $-0,51(0,207)$ & 10,48 & 3,75 & $-1,40$ \\
\hline $40-49$ & $0,75(<0,001)$ & $-4,81(0,004)$ & $-0,14(0,534)$ & $-0,30(0,561)$ & 15,13 & 7,07 & 4,08 \\
\hline Total & $1,04(<0,001)$ & $-6,90(0,001)$ & $-0,04(0,891)$ & $-0,71(0,270)$ & 20,92 & 9,35 & 2,23 \\
\hline \multicolumn{8}{|l|}{ Veículo } \\
\hline \multicolumn{8}{|l|}{ Sexo } \\
\hline Masculino & $2,77(0,733)$ & $-2,32(<0,001)$ & $0,86(0,110)$ & $-0,10(0,883)$ & 17,15 & 22,82 & 21,79 \\
\hline Feminino & $0,89(0,626)$ & $-1,59(<0,001)$ & $0,34(0,080)$ & $0,22(0,389)$ & 5,48 & 8,56 & 10,71 \\
\hline \multicolumn{8}{|c|}{ Faixa etária (anos) } \\
\hline $15-19$ & $0,94(0,938)$ & $-0,30(<0,001)$ & $0,36(0,166)$ & $-0,11(0,735)$ & 5,60 & 8,20 & 7,07 \\
\hline $20-29$ & $1,48(0,914)$ & $-2,11(<0,001)$ & $0,68(0,035)$ & $-0,20(0,629)$ & 8,95 & 12,44 & 10,46 \\
\hline $30-39$ & $1,46(0,841)$ & $-1,17(<0,001)$ & $0,22(0,394)$ & $0,10(0,766)$ & 8,97 & 10,64 & 11,65 \\
\hline $40-49$ & $1,35(0,507)$ & $-2,09(<0,001)$ & $0,34(0,319)$ & $-0,16(0,713)$ & 8,67 & 9,00 & 7,36 \\
\hline Total & $1,82(0,688)$ & $-1,96(<0,001)$ & $0,60(0,084)$ & $0,07(0,877)$ & 11,23 & 15,66 & 16,35 \\
\hline
\end{tabular}

* Todas as categorias de acidentes de trânsito. 


\section{Figura 2}

Modelos ajustados da análise de tendência das taxas de mortalidade por acidentes de trânsito geral e por veículo a motor (por 100 mil habitantes), por idade e sexo. Paraná, Brasil, 1980 a 2014.

2a) Geral *

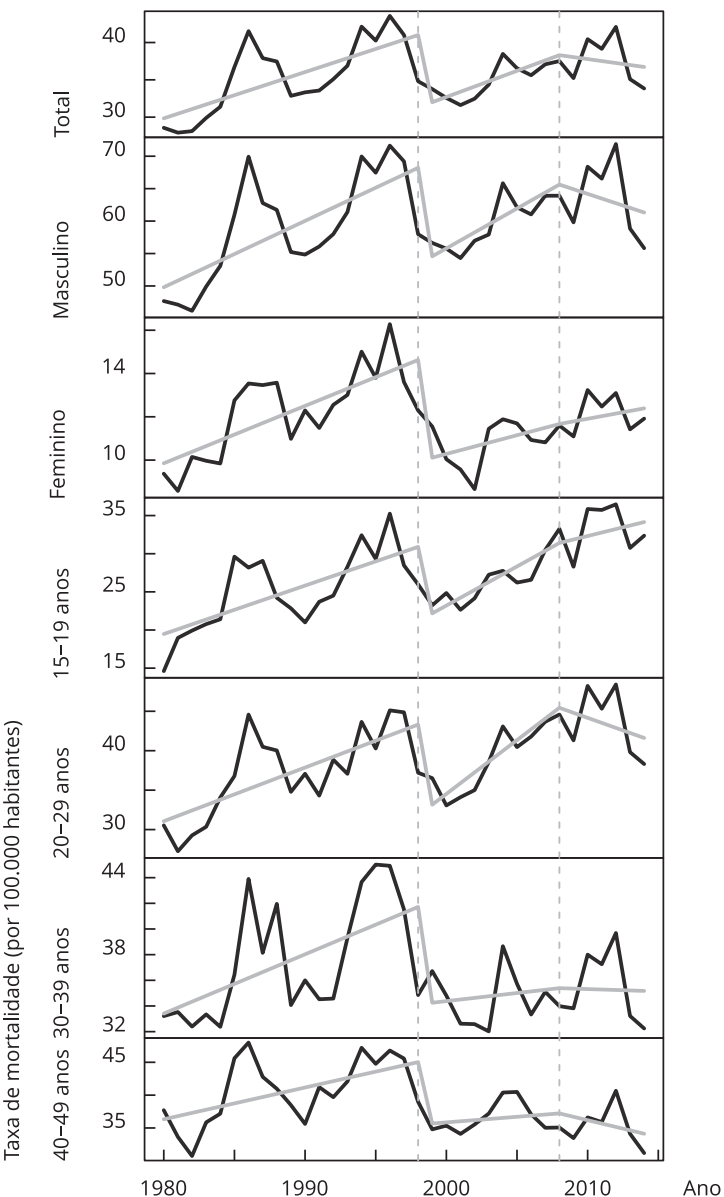

2b) Veículo

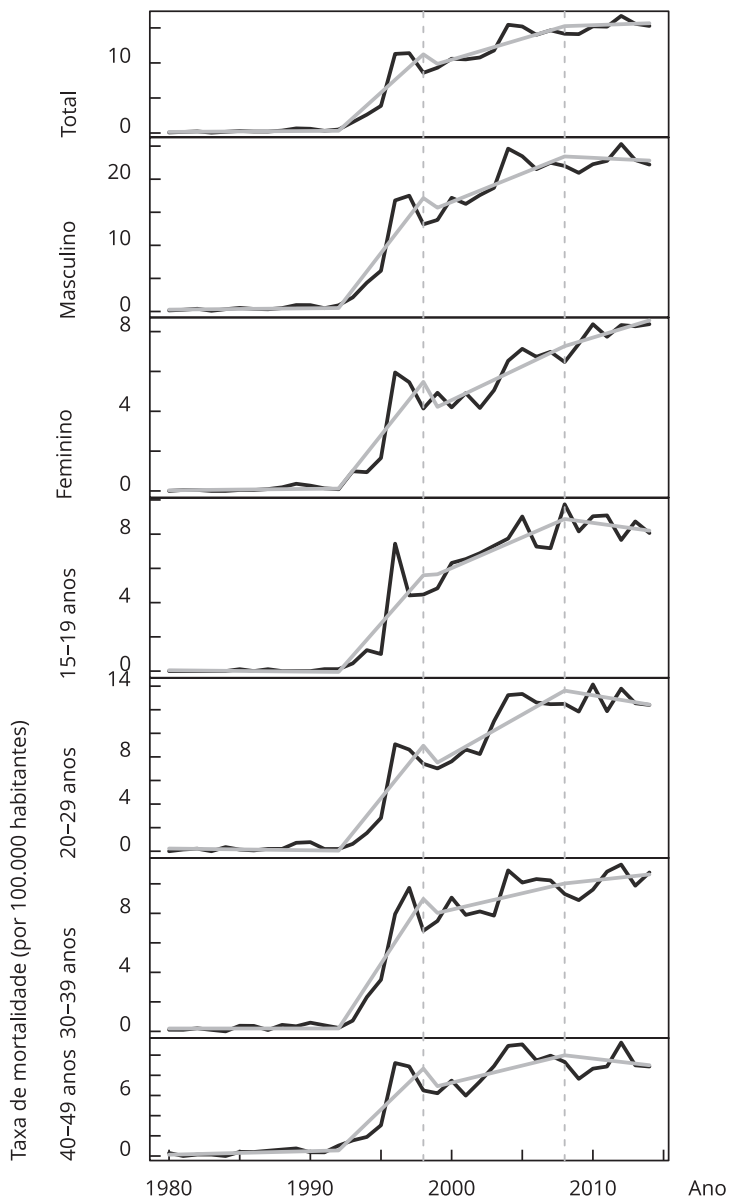

* Todas as categorias de acidentes de trânsito.

Nota: linha escura contínua: série observada; linha cinza clara contínua: modelo estimado; linhas cinza tracejadas verticais: 1998 - implantação do Código de Trânsito Brasileiro 9; 2008 - implantação da Lei Seca 10.

ano de implantação do CTB, verificaram-se reduções acentuadas das taxas de mortalidade para todas as categorias das vítimas, exceto para motociclista, que apresentou tendência ascendente em toda a análise. Por outro lado, o impacto da implantação da Lei Seca em 2008 foi menos acentuado. As tendências de aumento foram amenizadas e ocorreu declínio na tendência de mortalidade para todos os acidentes de trânsito, veículo e pedestre, contudo somente as taxas de mortalidade para os pedestres mantiveram tendência de declínio, as taxas para as demais categorias voltaram a aumentar logo após a implantação dessa lei (Tabela 1, Figuras 2 e 3). 
Figura 3

Modelos ajustados segundo as taxas de mortalidade de motociclistas e pedestres (por 100 mil habitantes), por idade e sexo. Paraná, Brasil, 1980 a 2014.

3c) Motociclista

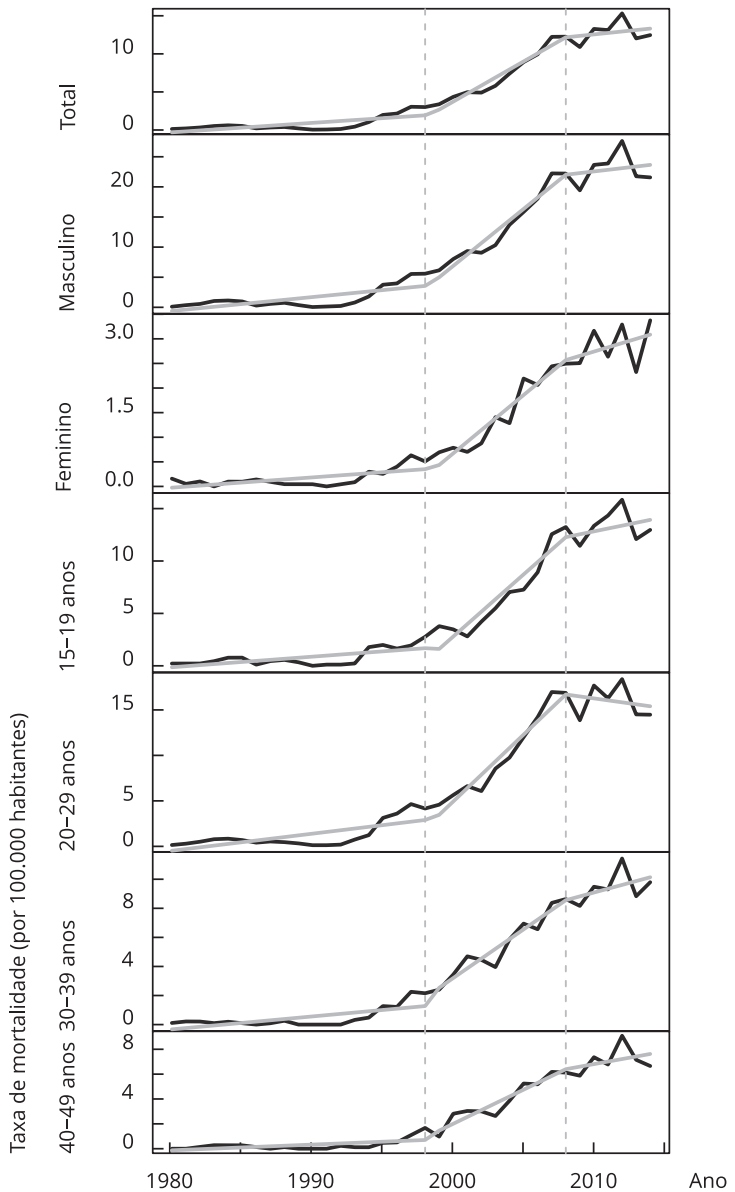

3d) Pedestre

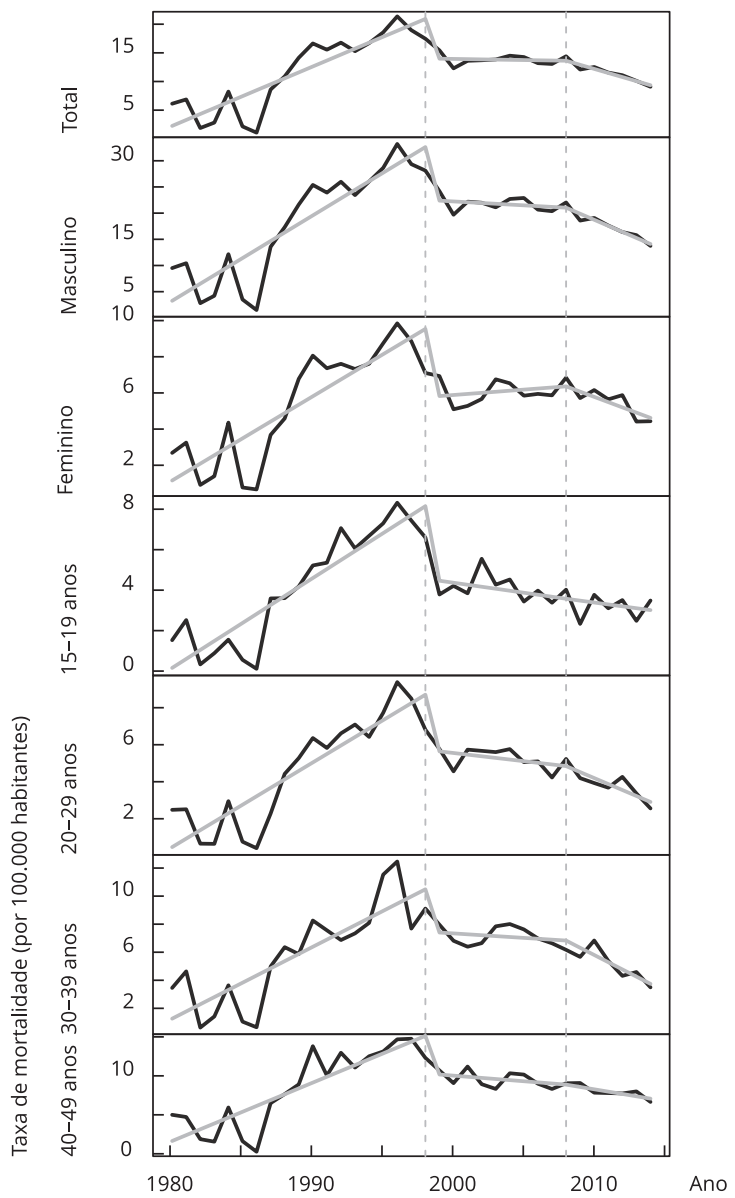

* Todas as categorias de acidentes de trânsito.

Nota: linha escura contínua: série observada; linha cinza clara contínua: modelo estimado; linhas cinza tracejadas verticais: 1998 - implantação do Código de Trânsito Brasileiro 9; 2008 - implantação da Lei Seca 10.

\section{Discussão}

A presente análise da mortalidade por acidentes de trânsito mostrou não somente as taxas de óbitos, mas também a importância do CTB e da Lei Seca no impacto da magnitude e da tendência dessas taxas no Estado do Paraná. Pode-se afirmar que os resultados mostram que essas leis foram determinantes para a prevenção dos óbitos por acidentes trânsito. Este estudo destaca que a morte no trânsito é prematura e evitável e acomete a faixa da população em idade economicamente ativa, que se constitui em fonte provedora de suas famílias, com perda para a sociedade e prejuízo multissetorial para o país. Apresenta ainda a importância dos acidentes trânsito como problema de saúde pública, chamando a atenção para a gravidade da ocorrência em ocupantes de motocicletas, a população masculina em geral e, sobretudo, em jovens. 
As evidências quanto à redução de óbitos por acidentes de trânsito, mediante a adoção de medidas legislativas, foram constatadas nos Estados Unidos, onde ocorreu diminuição nas taxas de mortalidade em até $24 \%$ após aplicação de normas legais mais rígidas quanto à ingestão de álcool pelos motoristas 22. Considerando esses dados, em relação ao Brasil, nos últimos anos foram tomadas medidas de caráter legislativo na tentativa de conter o alto número de acidentes 23 .

Nessa perspectiva, constatou-se no Estado do Paraná uma redução nas taxas de mortalidade por acidentes de trânsito logo após a implantação do CTB, em 1998. No entanto, os coeficientes de mortalidade aumentaram nos anos posteriores a 2005. Para o conjunto das capitais brasileiras, também se encontrou aumento das taxas de mortalidade a partir de 2001, tendo em vista que o fato pode estar associado à perda de eficiência na fiscalização e aplicação das punições aos infratores 24. Estudo de série histórica que analisou o impacto do CTB nas regiões do Brasil revelou redução nas taxas de óbitos por acidentes de trânsito logo após a sua implantação, em 1998. Todavia, o CTB não teve o impacto esperado, uma vez que a mortalidade diminuiu apenas até o ano de 2005, não atingindo os níveis de países com legislação de trânsito semelhante à brasileira 25 .

Neste estudo, o maior impacto sobre a mortalidade parece estar relacionado com a implantação do CTB, uma vez que a redução nas taxas foi mais elevada no ano imediatamente posterior à sua implantação. Isso é consistente com estudo nacional que analisou o impacto imediato do CTB sobre a redução de lesões e mortes relacionadas ao trânsito nas estradas interestaduais brasileiras e identificou uma redução de $21,3 \%$ dos acidentes e de $24,7 \%$ nas mortes imediatas, salvando 5.962 vidas nas estradas do país 25. Entretanto, após 1999, observou-se que praticamente não houve mais reduções nas taxas de mortalidade atribuíveis às normas do CTB, fato que pode estar relacionado ao relaxamento na supervisão e no fiel cumprimento das sanções previstas na legislação 25.

Os achados referentes ao predomínio nas taxas de mortalidade por acidentes de trânsito para o sexo masculino e jovens de ambos os sexos são semelhantes a outros estudos 26,27,28. Esse perfil talvez seja consequência da maior exposição masculina e de jovens no trânsito, bem como por comportamentos determinados social e culturalmente, que os fazem assumir maiores riscos na condução de veículos, como maior velocidade, manobras mais arriscadas, uso de álcool, entre outros 27 .

Em relação à frota de veículos no Brasil, entre os anos de 1998 a 2014, ela dobrou, passando de 24 milhões para 57 milhões de veículos 29 . Em relação aos estados, o Paraná tem a terceira maior frota de veículos do Brasil, com crescimento de 103\% entre 2004 e 2014, passando de 3,2 milhões para 6,5 milhões de veículos ${ }^{30}$. Pesquisas referem que, com o aumento de veículos nas vias públicas, surge um importante problema social: a maior ocorrência de acidentes de trânsito 31.

A motocicleta foi o tipo de veículo que mais aumentou no Brasil, saltando de 4,5 milhões para 22,8 milhões entre 2001 e 2014 29, salto justificado por ser uma opção de transporte mais econômica tanto de aquisição quanto de consumo de combustível e manutenção, comparada a outros veículos automotores, além das facilidades de tráfego e estacionamento. Nesse contexto, tem sido verificado nos últimos anos um aumento de sua utilização como instrumento de trabalho na entrega de mercadorias, medicamentos, alimentos ou documentos, e até mesmo no transporte de passageiros 32 .

Neste estudo, 76,9\% do total dos óbitos ocorreram em motociclistas. A tendência crescente dos óbitos de motociclista também tem sido encontrada na Grã-Bretanha, com aumento anual de 4,6\% de internações de acidentados 33. No Brasil, estudo realizado em Campinas, Estado de São Paulo registrou aumento expressivo dos acidentes de trânsito fatais com motociclistas, passando a representar, em 2008, 49,3\% dos óbitos no trânsito 34 .

Apesar de o presente estudo não ter dados sobre condições ambientais no momento do acidente, enfatiza-se a vulnerabilidade dos condutores de motocicletas às adversidades meteorológicas ${ }^{32}$, pela necessidade de estabilidade e equilíbrio exigida por esse veículo. A letalidade mais elevada para os pedestres e ocupantes de motocicletas está associada à possibilidade de ambos sofrerem graves traumatismos múltiplos crânio-encefálicos e de coluna devido à ausência de proteção 35,36 . O corpo do motociclista, exceto a cabeça, protegida por capacete, fica totalmente vulnerável ao impacto, podendo ocorrer lesões múltiplas 37 . Motociclistas e pedestres se constituem no grupo de usuários da via pública mais vulnerável em termos de exposição corpórea a lesões em caso de acidentes 27.

Neste estudo, observou-se declínio na tendência das taxas de mortalidade por acidentes de trânsito logo após a implantação da Lei Seca e, posteriormente, houve aumento, concordando com resultados de um estudo nacional que analisou a frequência de adultos que dirigiram após consumo de 
bebidas alcoólicas em 27 cidades brasileiras. Os autotres indentificaram uma queda inicial logo após a implantação da lei, seguida pela retomada do crescimento nos meses de novembro e dezembro de 2008 12. Por outro lado, estudos internacionais descrevem um declínio contínuo no número de mortes com uma fiscalização adequada e penalidades mais severas para os condutores que apresentaram nível de alcoolemia além do permitido 6,7,22.

Duailibi et al. 38 realizaram estudo com 908 motoristas nas principais vias de trânsito de Diadema, Estado de São Paulo, de fevereiro de 2005 a março de 2006, e identificaram que 85\% de jovens candidatos à primeira habilitação não conheciam alguém que tinha sido punido legalmente por beber e dirigir, $74 \%$ acreditavam que nenhum infrator receberia a pena legal e $64 \%$ consideravam mínima a chance de ser parado por policial ou sujeito a penalidades. Estudo realizado em Porto Alegre, Rio Grande do Sul, analisou o comportamento de risco para acidentes de trânsito em jovens antes e depois da implementação de lei que proíbe o consumo de bebidas alcoólicas em postos de gasolina e identificou que apesar de $86 \%$ dos entrevistados referirem ter bebido e dirigido no último ano, apenas $9 \%$ relataram que foram abordados para realizar teste de alcoolemia 39.

Estudos que mostram o impacto de políticas públicas específicas na ocorrência de acidentes de trânsito são relevantes, já que evidenciam tanto ao poder público quanto à população em geral o alcance e a efetividade das medidas legais instituídas.

Contínua fiscalização pelas autoridades, especialmente nos horários e locais de maior risco de acidentes de trânsito, a ágil aplicação das medidas punitivas, restrições maiores para motoristas novatos e a instalação de sistemas de bloqueio da ignição dos veículos em caso de bafômetro positivo 40 , são algumas medidas que podem também impactar na ocorrência de acidentes de trânsito.

Algumas considerações devem ser feitas em relação à qualidade dos bancos de dados, considerando que o uso das estatísticas de mortalidade vem aumentando por causa das crescentes demandas de conhecimento da dinâmica demográfica e de saúde da população 41. Pesquisas apontam a necessidade de melhorar o preenchimento das declarações de óbitos e realização de capacitações para as equipes responsáveis pelo processamento dos dados de mortalidade 42 . O uso dos sistemas de informações em saúde do SUS é fundamental para o acompanhamento continuado da situação epidemiológica e melhor compreensão do impacto dos acidentes na morbidade e na mortalidade, e contribuem para a elaboração de estratégias de prevenção 43.

Os achados deste estudo ampliam as discussões relativas a prevenção dos acidentes de trânsito e suas consequências por intermédio de políticas públicas. Todavia, elas não bastam como elementos únicos e/ou estanques para que o fenômeno seja minorado em escala significativa. Tornam-se importantes a manutenção e a ampliação da fiscalização, além de medidas de comunicação e educação de forma continuada, sistemática e abrangente tanto no alcance populacional quanto na compreensão das linguagens e valores dos mais variados setores socioculturais, para que não haja retrocessos.

\section{Colaboradores}

D. R. O. M. Abreu e T. A. F. Mathias participaram da concepção, análise dos dados e elaboração do manuscrito. E. M. Souza colaborou na análise e interpretação dos dados.

\section{Agradecimentos}

Os autores agradecem ao Conselho Nacional de Desenvolvimento Científico e Tecnológico (CNPq) pela concessão de bolsa de doutorado que viabilizou a realização do trabalho. 


\section{Referências}

1. World Health Organization. Global status report on road safety 2013: supporting a decade of action. Geneva: World Health Organization; 2013.

2. Bhalla K, Shotten M, Cohen A, Brauer M, Shahraz S, Burnett R, et al. Transport for health: the global burden of disease 504 from motorized road transport. Washington DC: World Bank Group; 2014.

3. Waiselfisz JJ. Mapa da violência: acidentes de trânsito e motocicleta. Rio de Janeiro: Centro Brasileiro de Estudos Latino-Americanos/Faculdade Latino-Americana de Ciências Sociais; 2013.

4. Departamento de Análise de Situação em Saúde, Secretaria de Vigilância em Saúde, Ministério da Saúde. Saúde Brasil 2010: uma análise da situação de saúde e de evidências selecionadas de impacto de ações de vigilância em saúde. Brasília: Ministério da Saúde; 2011.

5. Minayo MC, Souza ER. Violence and health care as an interdisciplinary field and an arena for collective action. Hist Ciênc Saúde-Manguinhos 1997; 4:513-31.

6. Nakahara S, Katanoda K, Ichikawa M. Onset of a declining trend in fatal motor vehicle crashes involving drunk-driving in Japan. J Epidemiol 2013; 23:195-204.

7. Bahadorimonfared A, Soori H, Mehrabi Y, Delpisheh A, Esmaili A, Salehi M, et al. Trends of fatal road traffic injuries in Iran (2004-2011). PLoS One 2013; 8:e65198.

8. Haojie Li, Graham DJ. Heterogeneous treatment effects of speed cameras on road safety. Accid Anal Prev 2016; 97:153-61.

9. Brasil. Lei no 9.503, de 23 de setembro de 1997. Institui o Código de Trânsito Brasileiro. Diário Oficial da União 1997; 24 set.

10. Brasil. Lei no 11.705 , de 19 de junho de 2008 : altera a Lei no 9.503, de 23 de setembro de 1997, que "institui o Código de Trânsito Brasileiro", e a Lei no 9.294, de 15 de julho de 1996, que dispõe sobre as restrições ao uso e à propaganda de produtos fumígeros, bebidas alcoólicas, medicamentos, terapias e defensivos agrícolas, nos termos do § 4o do art. 220 da Constituição Federal, para inibir o consumo de bebida alcoólica por condutor de veículo automotor, e dá outras providências. Diário Oficial da União 2008; 20 jun.
11. Traumann T. Paz na estrada. Veja 1998; (1536): 68-9.

12. Moura EC, Malta DC, Morais Neto OL, Penna GO, Temporão JG. Direção de veículos motorizados após consumo abusivo de bebidas alcoólicas, Brasil, 2006 a 2009. Rev Saúde Pública 2009; 43:891-4.

13. Mello-Jorge MHP, Koizumi MS. Acidentes de trânsito causando vítimas: possível reflexo da lei seca nas internações hospitalares. Revista ABRAMET 2009; 27:16-25.

14. Secretaria de Vigilância em Saúde, Ministério da Saúde. Projeto Vida no Trânsito (PVT). http://portalsaude.saude.gov.br/index.php/oministerio/principal/leia-mais-o-ministerio/ 711 -secretaria-svs/vigilancia-de-a-a-z/ violencia-e-acidentes/11512-projeto-vidano-transito (acessado em 16/Jul/2017).

15. Organização Mundial da Saúde. Manual da classificação estatística internacional de doenças, lesões e causas de óbito. 9a Rev. v. 1. São Paulo: Centro da OMS para a Classificação de Doenças em Português; 1985.

16. Organização Mundial da Saúde. Classificação estatística internacional de doenças e problemas relacionados à saúde. 10a Rev. São Paulo: Edusp; 1994.

17. Morettin PA, Toloi CMC. Análise de séries temporais. São Paulo: Edgard Blücher; 2004.

18. Cryer JD, Chan KS. Time series analysis: with applications in R. 2nd Ed. New York: Springer; 2008.

19. Chatfield C. The analysis of times series: an introduction. London: Chapman and Hall; 2003.

20. Durbin J, Watson GS. Testing for serial correlation in least squares regression. Biometrika 1951; 38:159-77.

21. Cochrane D, Orcutt GH. Application of least squares regression to relationships containing auto-correlated error terms. J Am Stat Assoc 1949; 44:32-61.

22. McMillan GP, Laphams S. Effectiviness of bans and laws in reducing traffic deaths: legalized Sunday packaged alcohol sales and alcohol-related traffic crashes and crash fatalities in New Mexico. Am J Public Health 2006; 96:1944-8. 
23. Bacchieri G, Barros AJD. Traffic accidents in Brazil from 1998 to 2010: many changes and few effects. Rev Saúde Pública 2011; 45:949-63.

24. Mello-Jorge MHP, Koizumi MS, Tuono VL. Acidentes de trânsito no Brasil: a situação nas capitais. São Paulo: Associação Brasileira de Medicina de Tráfego; 2008.

25. Departamento de Análise de Situação de Saúde, Secretaria de Vigilância em Saúde, Ministério da Saúde. Saúde Brasil 2004: uma análise da situação de saúde. Brasília: Ministério da Saúde; 2004.

26. Figueiredo LFP, Rasslan S, Bruscagin V, Cruz R, Silva MR. Increases in fines and driver licence withdrawal have effectively reduced immediate deaths from trauma on Brazilian roads: first-year report on the new traffic code. Injury 2001; 32:91-4.

27. Nunn S. Death by motorcycle: background, behavioral, and situational correlates of fatal motorcycle collisions. J Forensic Sci 2011; 56:42937.

28. Andrade SM, Mello-Jorge MHP. Características das vítimas por acidentes de transporte terrestre em município da Região Sul do Brasil. Rev Saúde Pública 2000; 34:149-56.

29. Rodrigues JM. Estado da motorização individual no Brasil - relatório 2015. http://www. observatoriodasmetropoles.net/download/ automoveis_e_motos2015.pdf (acessado em 16/Jul/2017).

30. Departamento Estadual de Trânsito do Paraná. Crescimento da frota de veículos no Paraná desacelerou em 2014. http://www.detran.pr.gov. $\mathrm{br} / \mathrm{modules} /$ noticias/article.php?storyid=1453 (acessado em 16/Jul/2017).

31. Marin L, Queiroz MS. A atualidade dos acidentes de trânsito na era da velocidade: uma visão geral. Cad Saúde Pública 2000; 16:7-21.

32. Silva DW, Andrade SM, Soares DA, Nunes EFPA, Melchior R. Condições de trabalho e riscos no trânsito urbano na ótica de trabalhadores motociclistas. Physis (Rio J.) 2008; 18:339-60.

33. Lyons RA, Ward H, Brunt H, Macey S, Thoreau $\mathrm{R}$, Bodger OG, et al. Using multiple datasets to understand trends in serious road traffic causalities. Accid Anal Prev 2008; 40:1406-10.
34. Marín-León L, Belon AP, Barros MBA, Almeida SDM, Restitutti MC. Ttendência dos acidentes de trânsito em Campinas, São Paulo, Brasil: importância crescente dos motociclistas. Cad Saúde Pública 2012; 28:39-51.

35. Santos AMR, Moura MEB, Nunes BMVT, Leal CFS, Teles JBM. Perfil das vítimas de trauma por acidente de moto atendidas em um serviço público de emergência. Cad Saúde Pública 2008; 24:1927-38.

36. Gawryszewski VP, Coelho HMM, Scarpelini S, Zan R, Mello-Jorge MHP, Rodrigues SEM. Perfil dos atendimentos a acidentes de transporte terrestre por serviços de emergência em São Paulo. Rev Saúde Pública 2009; 43:275-82.

37. Teixeira JRB, Santos NA, Sales ZN, Moreira RM, Boery RNSO, Boery EN, et al. Utilização dos equipamentos de proteção individual por mototaxistas: percepção dos fatores de risco e associados. Cad Saúde Pública 2014; 30:885-90.

38. Duailibi S, Ponicki W, Grube J, Pinsky I, Laranjeira R, Raw M. The effect of restricting opening hours on alcohol related violence. Am J Public Health 2007; 97:2276-80.

39. De Boni R, Leukefeld C, Pechansky F. Young people's blood alcohol concentration and the alcohol consumption city law, Brazil. Rev Saúde Pública 2008; 42:1101-4.

40. World Health Organization. Drinking and driving: a road safety manual for decision-makers and practitioners. Geneva: World Health Organization; 2007.

41. Mathias TAF, Aidar T. Diferencial de mortalidade na população idosa em um município da região Sul do Brasil, 1979-2004. Ciênc Cuid Saúde 2010; 9:44-51.

42. Lozada EMK, Mathias TAF, Andrade SM, Aidar T. Informações sobre mortalidade por causas externas e eventos de intenção indeterminada, Paraná, Brasil, 1979 a 2005. Cad Saúde Pública 2009; 25:223-8.

43. Malta DC, Silva MMA, Barbosa J. Violências e acidentes, um desafio ao Sistema Único de Saúde. Ciênc Saúde Coletiva 2012; 17:2220-1. 


\section{Abstract}

The objective was to analyze the impact of the Brazilian Traffic Code and the Law Against Drinking and Driving on mortality from traffic accidents in the State of Paraná, Brazil, from 1980 to 2014. This was an ecological time series study on mortality from traffic accidents in residents 15 to 49 years of age, stratified by the sex, age, and categories of victims, with data from the Mortality Information System. The time trend study used a segmented linear regression model and the Cochrane-Orcutt iterative procedure. The assumption of independence of residuals was verified by correlograms and the Box-Pierce test. The highest mortality rates during the period were in males 20 to 29 years of age. After enactment of the Brazilian Traffic Code, there was a decrease of 9.69 deaths/100,000 inhabitants per year for all categories of traffic accidents $(p<0.001), 6.90$ for pedestrians $(p=0.001)$, and 1.96 for vehicle occupants $(p<0.001)$. As for age bracket, the greatest impact on mortality was in pedestrians 15 to 19 years of age $(p<0.001)$ and all victims 20 to 29 years of age $(p<0.001)$. Following enactment of the Drinking and Driving Law, the data displayed variability and the trends were not significant. However, there was a decrease in overall and pedestrian mortality. The rates for motorcyclists and vehicle occupants stabilized. The results showed an impact on traffic accident mortality after enactment of the new Brazilian Traffic Code and Drinking and Driving Law, followed by an increase in the rates. The study evidenced the need for more effective enforcement and progress with public policies in order to avoid a reversal of the gains achieved.

Traffic Accidents; Health Evaluation; Mortality; Time Series Studies

\section{Resumen}

El objetivo fue analizar el impacto del Código de Tráfico Brasileño (CTB) y la Ley Seca en la mortalidad por accidentes de tráfico, en el Estado de Paraná, Brasil, durante el período de 1980 a 2014. Se trata de un estudio ecológico de series temporales sobre las tasas de mortalidad por accidentes de tráfico, de residentes de 15 a 49 años, por sexo, edad y categorías de las víctimas, con datos del Sistema de Informaciones sobre Mortalidad. El estudio de la tendencia se realizó mediante un modelo de regresión lineal segmentada y por el procedimiento interactivo de Cochrane-Orcutt. El presupuesto de independencia de los residuos se verificó mediante correlogramas y el test de Box-Pierce. Durante todo el período, las mayores tasas de mortalidad se observaron para el sexo masculino, motociclistas y una franja de edad de 20 a 29 años de edad. Tras la implantación del CTB, hubo una reducción de 9,69 óbitos por año, en todas las categorías de accidentes de tráfico $(p<0,001)$, de 6,90 en peatones ( $p=0,001) y$ de 1,96 en ocupantes de vehículo ( $p$ $<0,001)$. En cuanto a la franja de edad, el mayor impacto en la mortalidad se observó desde los 15 a los 19 años en peatones $(p<0,001) y$ entre 20 a 29 años en todas las categorías $(p<0,001)$. Tras la Ley Seca, los datos presentaron variabilidady las tendencias no fueron significativas. No obstante, hubo una disminución de la mortalidad en la categoría general y peatones. En las categorías de motociclista y vehículo, hubo una estabilización de las tasas. Los resultados muestran impacto en las tasas de mortalidad por accidentes de tráfico, tras la implantación del CTB y la Ley Seca, con un posterior aumento de las mismas. Se evidencia una demanda de efectividad en la fiscalización de las leyes y el avance en las politicas públicas para que no haya retroceso en lo ya realizado.

Accidentes de Tránsito; Evaluación en Salud; Mortalidad; Estudios de Series Temporales
Recebido em 17/Jul/2017

Versão final reapresentada em 20/Fev/2018

Aprovado em 23/Fev/2018 